\title{
O GÊNERO MEMORIAL DESCRITIVO: RELATO DE UMA EXPERIÊNCIA DE ENSINO
}

\author{
Descriptive Memorial Genre: El género memorial: \\ A Teaching Experience Report un relato de experiencia de enseñanza
}

\author{
Ema Marta Dunck Cintra* \\ Instituto Federal de Goiás, Departamento de Áreas Acadêmicas I, Goiânia, GO, Brasil
}

\begin{abstract}
Resumo: O memorial descritivo registra e reflete sobre a construção da identidade pessoal, sobre a formação e profissão das pessoas. É um gênero que faz parte do mundo do trabalho e do mundo acadêmico e deve, por isso, ser ensinado. Este relato de experiência, pautado em uma abordagem qualitativa (MARTINS, 2004), revisão bibliográfica e pesquisa-ação (THIOLENT, 1988), descreve a prática de produção da escrita de um memorial descritivo por estudantes do $6^{\circ}$ semestre do curso superior em Secretariado Executivo do IFMT/Cuiabá, na disciplina Língua Portuguesa VI. Trata-se de uma proposta didática construída no desenrolar das aulas, envolvendo as estruturas cognitivas que os estudantes já dominavam (MOREIRA, 2011) e tendo como alicerce a teoria do gênero de discurso (BAKHTIN, 2000). Os resultados obtidos focam, sobretudo, no processo que levou à produção escrita do memorial.
\end{abstract}

Palavras-Chave: Gênero discursivo. Memorial descritivo. Proposta Didática.

\begin{abstract}
A descriptive memorial registers and reflects over the construction of a personal identity, abaout people's education and profession. This genre has relation to the academic and labor universe and, for that reason, it should be taught to the community. This experience report, based on a qualitative approach (MARTINS, 2004), with a bibliographic review and an action research (THIOLENT, 1988), describes the practice of a written production in respect of a descriptive memorial done by sixth semester students of Brazilian Portuguese Language VI subject in the IFMT/Cuiabá Executive Secretary undergraduate course. It comes to be a didactic proposal developed during the classes, involving cognitive structures that the students had already mastered (MOREIRA, 2011), and yet supported by the Discursive Genres Theory (BAKHTIN, 2000). The results focus, mainly, in the process that led to the memorial written production.
\end{abstract}

Keywords: Discursive Genre. Descriptive memorial. Didactic proposal.

Resumen: El memorial registra y reflexiona sobre la construcción de identidade personal, sobre la formación y profesión de personas. Es un género textual que hace parte del mundo del trabajo y del mundo académico y por ello debe ser enseñado. Este relato de experiencia está basado en un abordaje cualitativo (MARTINS, 2004), revisión bibliográfica e investigación-acción (THIOLENT, 1988), y describe la práctica de producción escrita de un memorial por estudiantes del $6^{\circ}$ semestre del curso superior Secretariado Ejecutivo de IFMT/Cuiabá, en la asignatura Lengua Portuguesa VI. Esta propuesta didáctica ha sido diseñada en el desarrollo de las clases, considerando las estructuras cognitivas que los estudiantes tienen dominio (MOREIRA, 2011), y su base es la teoría de géneros de discurso (BAKHTIN, 2000). Los resultados obtenidos enfocan especialmente el processo de la producción escrita del memorial.

Palabras clave: Género discursivo. Memorial descriptivo. Propuesta didáctica.

* Docente do Curso de Letras no Instituto Federal de Goiás (IFG) - Departamento de Áreas Acadêmicas I.

Campus Goiânia. ORCID: https://orcid.org/0000-0002-0888-3747. E-mail: ema.cintra@ifg.edu.br. 
$\mathrm{Na}$ atualidade o ensino da língua materna precisa se valer dos gêneros que circulam socialmente tanto nas esferas do cotidiano quanto nas acadêmicas e profissionais. Os gêneros têm-se tornado uma forma bem produtiva para o desenvolvimento da linguagem, quer na educação básica, quer no ensino superior, pois permitem atrelar a assimilação do gênero discursivo diretamente ao contexto no qual ele está inserido, possibilitando um aprender com mais sentido para os estudantes.

Há uma multiplicidade de gêneros que circulam na academia, tais como o artigo científico (NBR 6022), o relatório técnico (NBR 10719), a resenha e resumo (NBR 6028), o projeto de pesquisa (NBR 15287), entre outros mais utilizados, e que são ensinados e trabalhados de forma bem fértil. No entanto, é escasso o material produzido sobre como trabalhar o gênero memorial descritivo nos cursos superiores.

Rego (2014, p. 3) refere-se ao memorial como uma "espécie de autobiografia intelectual e profissional de professores universitários e costuma ser exigido nos processos seletivos ou de ascensão na carreira acadêmica". No entanto, segundo Rego (2014, p. 3), apesar de ser uma "fonte fecunda para a pesquisa de diferentes âmbitos, os memoriais não têm sido suficientemente explorados". E completa dizendo que prepondera "uma significativa escassez de estudos e debates em torno do tema e uma ausência de orientações institucionais mais claras sobre como fazer os memoriais" (REGO, 2014, p. 9).

Em 2016, ao ser planejado o trabalho para estudantes do sexto semestre do curso de Bacharelado em Secretariado Executivo do Instituto Federal de Mato Grosso - IFMT -, verificou-se o que continha na ementa da respectiva disciplina: "Gêneros textuais da esfera acadêmica: artigo científico, memorial descritivo. Textualidade e estilo: continuidade e progressão textual. A impessoalidade nos textos científicos".

De imediato sentiu-se certo temor em encarar essa responsabilidade, dado que se fazia necessário pensar em uma forma eficiente de trabalhar tal gênero visando não só a promoção de sua apropriação por parte dos estudantes como também colaborar para a sua formação. Partia-se, desse modo, de incertezas, como apontado por Morin (2014, p. 59), que diz: "Conhecer e pensar não é chegar a uma verdade absolutamente certa, mas dialogar com a incerteza". Dialogando, pois, com incertezas, foi aceito o desafio de pensar em uma proposta plausível para o ensino desse gênero, tendo sempre em mente sua importância para o curso e para a formação profissional dos alunos.

Inicialmente foram selecionados livros que tratam sobre o ensino da língua portuguesa no nível superior e sites educacionais (de faculdades e pós-graduação) que abordavam esse gênero. Dos livros levantados e que circulam na academia, apenas três faziam referência em seu título ao trabalho com o gênero memorial, sendo um deles um dicionário de gêneros.

\footnotetext{
${ }^{1}$ Este artigo refere-se a uma prática pedagógica desenvolvida em 2016 quando eu era docente da área de Letras no Instituto Federal de Mato Grosso (IFMT) - Departamento da Área de Bases Comum e Mestrado em Educação Profissional e Tecnológica em Rede Nacional - ProfEPT. Campus Cuiabá/MT.
} 
Um dos livros, o de Severino (2016, p. 243), pontua que o memorial é uma "retomada articulada e intencionalizada dos dados do currículo vitae do estudioso, do qual sua trajetória acadêmico-profissional fora montada e documentada". No memorial, é relevante tratar de modo mais qualitativo a vida profissional da pessoa, e se "constitui, pois, em uma autobiografia, configurando-se como uma narrativa simultaneamente histórica e reflexiva". Severino (2016, p. 245) ainda enfatiza que o autor do memorial deve se preocupar em ressaltar os "posicionamentos práticos e teóricos" que foram sendo construídos em cada fase de sua vida, registrando sua evolução.

O segundo livro, o de Oliveira (2012, p. 121), descreve o memorial como sendo um "[...] documento escrito relativo à lembrança, à vivência de alguém; memórias. Deve conter um breve relato sobre a história de vida pessoal, profissional e cultural do memorialista; por isso mesmo é escrito com o uso da primeira pessoa". Oliveira (2012, p. 121) explicita para que o memorial serve e assinala que ele é importante para auxiliar na elaboração do TCC, porque é um "recurso para o levantamento de dados durante o curso universitário".

O autor também traz dicas de procedimentos de registro de estudo dos acadêmicos e, por fim, apresenta um memorial "que pode ser utilizado como modelo pelo aluno com as devidas adaptações" (OLIVEIRA, 2012, p. 122). Nesse caso, houve a preocupação em deixar registrado um modelo de memorial que é solicitado na Universidade de Brasília UnB.

O terceiro livro é um dicionário, de autoria de Costa (2014, p. 168), que descreve o Memorial, no discurso acadêmico, como a produção escrita que "se assemelha a um Curriculum Vitae pelo conteúdo, já que faz um relato das principais atividades da vida profissional científica e acadêmica do indivíduo".

De modo geral, não se encontrou nesses livros orientação que pudesse auxiliar didaticamente no trabalho com esse gênero contemplando, sobretudo, estilo (traços enunciativos do autor/sequências textuais/tipos de discurso), construção composicional condições de produção, estrutura e aspectos linguísticos -, com exceção de conteúdo temático (o que é possível de dizer pelo gênero) (BAKHTIN, 2000), que foi em parte contemplado.

Quanto à busca em sites, ${ }^{2}$ evidenciou-se farto material sobre memorial descritivo voltado para a arquitetura ou para formação de professores. Mesmo assim, na área de arquitetura, ao contrário do esperado, os textos explicitavam os passos de desenvolvimento de uma edificação, detalhando todo o projeto a ser realizado. No caso dos memoriais de formação, eles tocavam, especialmente, em momentos vivenciados na academia, com uma reflexão sobre a teoria aprendida e a prática docente. Portanto, estes poderiam servir como base para uma análise dos elementos constitutivos de um enunciado e fornecer pistas na busca de estratégias para o trabalho com esse gênero.

\footnotetext{
${ }^{2}$ O memorial de Carlos Eduardo Vieira (2017) traz uma discussão sobre o exercício de transformar um discurso normalmente em $3^{\mathrm{a}}$ pessoa para a $1^{\mathrm{a}} \mathrm{e}$ o significado disso para aqueles que estão acostumados a ter uma produção escrita impessoal. O artigo de Cristina Teresa Rego (2014) aponta esse gênero como importante no meio acadêmico, mas lembra que é pouco explorado quando se trata do seu ensino.
} 
É importante salientar o entendimento de que, se a ementa do curso solicita o ensino desse gênero, isto se deve ao fato de no mundo do trabalho ou nos estudos posteriores desses futuros profissionais esse gênero ser requisitado e fazer parte dessas "esferas da atividade humana", conforme pontua Bakhtin (2000, p. 279). Por conseguinte, sente-se a obrigação de se debruçar nas possibilidades e selecionar situações nas quais ele é requerido e o que faz parte da sua escritura, no que diz respeito ao "conteúdo temático, estilo e construção composicional" (BAKHTIN, 2000, p. 279). Para tudo isso a teoria do gênero do discurso (BAKHTIN, 2000) pode auxiliar, ao se pensar em uma proposta para desenvolvimento da aula.

O memorial descritivo é um gênero que geralmente é exigido no ingresso aos estudos de pós-graduação ou entrada em determinados empresas. Dependendo do local/instituição onde o futuro profissional atuará, este poderá ter como uma das incumbências auxiliar na tarefa de analisar memoriais descritivos para as admissões.

Em suma, há a convicção de que se trata de gênero textual que convém ensinar aos estudantes.

É certo que, no ensino da língua com foco nos gêneros, a proposta deve não só considerar os aspectos estruturais do texto, mas também lançar um olhar efetivamente sobre os elementos de ordem social e histórica. Desse modo, é preciso atentar-se ao processo de escrita, a quem se escreve, ao lugar social de quem escreve e para quem se escreve, aos objetivos pretendidos, ao nível de linguagem e à organização geral do texto a ser preconizado e para qual situação (BAKHTIN, 2009³). Esses aspectos são bastante importantes e estão atrelados ao contexto sócio-histórico-cultural e às formas de dizer que circulam socialmente (BAKHTIN, 2000).

Assim, aos poucos, pode-se estabelecer alguns parâmetros, entre eles o de que o memorial a ser escrito deve abarcar o registro de memórias que possibilitem uma reflexão sobre a construção da identidade pessoal e profissional, historiando o percurso da vida, da formação acadêmica e da prática profissional para aqueles que já atuam no mercado de trabalho, apontando a prospecção para sua vida.

Após o estabelecimento desse recorte, a ação pode se efetivar.

Assim, este artigo tem o propósito de descrever uma experiência desenvolvida na produção de memorial descritivo com estudantes do curso superior em Secretariado Executivo do IFMT/Cuiabá, na disciplina Língua Portuguesa VI. Apresenta-se o desenvolvimento do processo, pautando-se, como já se referiu, em uma abordagem qualitativa (MARTINS, 2004), de natureza aplicada, utilizando para isso os procedimentos da pesquisa-ação (THIOLENT, 1988).

\footnotetext{
${ }^{3}$ Embora Bakhtin esteja citado como autor de Marxismo e filosofia da linguagem, consideramos Volóchinov como autor da obra mesmo que identifiquemos, na $13^{\text {a }}$ edição de 2009 , que a referência a ele apareça somente entre parênteses.
} 
Bakhtin (2009, p. 127) diz que "a interação verbal constitui assim a realidade fundamental da língua" e é "realizada através da enunciação ou das enunciações". Para o autor, a língua não é "constituída por um sistema abstrato de formas linguísticas nem pela enunciação monológica isolada, nem pelo ato psicofisiológico de sua produção" (BAKHTIN, 2009, p. 123). Portanto, é interação, "vive e evolui historicamente na comunicação verbal concreta, não no sistema linguístico abstrato das formas da língua nem no psiquismo individual dos falantes" (BAKHTIN, 2009, p. 128).

Com apoio nos postulados de Bakthin, compreende-se que a língua é uma ação efetivamente social, uma vez que se concretiza na comunicação, na interação entre os falantes. Nesse sentido, o autor nega o subjetivismo individualista, que preconiza que o ser humano é o centro de estudo da linguagem. Para ele, esse individualismo é inconcebível, posto que a língua sofre influência do contexto, da situação social imediata de interação.

Além disso, Bakhtin (2009) aponta que o enunciado é o resultado da interação verbal que decorre tanto de uma situação material concreta como pelo contexto mais amplo que envolve todas as condições de vida de uma comunidade linguística. Essa ideia coaduna, portanto, com uma concepção de linguagem como fenômeno social, histórico e ideológico.

Brandão (2002, p. 10), corroborando essa ideia, diz que a "visão da linguagem como interação social, em que o outro desempenha papel fundamental na constituição do significado, integra todo o ato de enunciação individual num contexto mais amplo", mostrando, portanto, "as relações intrínsecas entre o linguístico e o social". Ideia que é admitida por Hanks (2008, p. 64), que assinala o seguinte: “Os gêneros [são tratados] como elementos historicamente específicos da prática social, cujos traços definidores os vinculam a atos comunicativos situados".

Bakhtin (2000) argumenta que a apropriação da linguagem pelo sujeito ocorre nas "esferas de atividades de comunicação humana". E essas esferas, que são "tipos relativamente estáveis de enunciados", definem os gêneros discursivos. Marcuschi (2008, p. 155) acolhe tal afirmação, dizendo que "com essa posição teórica chegamos à união do gênero ao seu envolvimento social". E afirma que "não se pode tratar o gênero de discurso independentemente de sua realidade social e de sua relação com as atividades humanas".

São, portanto, inúmeras as atividades interativas do ser humano que possibilitam a conformação de vários gêneros. Nesse sentido, Bakhtin (2000, p. 279) vai dizer que:

\footnotetext{
A riqueza e a variedade dos gêneros do discurso são infinitas, pois a variedade virtual da atividade humana é inesgotável, e cada esfera dessa atividade comporta um repertório de gêneros do discurso que vai diferenciando-se e ampliando-se à medida que a própria esfera se desenvolve e fica mais complexa.
}

Esses gêneros são decorrentes, por certo, dessas atividades humanas e, como aponta Marcuschi (2008, p. 156), eles não podem ser vistos como "modelos estanques e nem como estruturas rígidas, mas como formas culturais e cognitivas de ação social corporificadas de modo particular na linguagem". Marcuschi (2008) reitera que os 
gêneros devem ser vistos como "entidades dinâmicas" que têm suas características demarcadas e que, por isso, levam a, conforme a situação comunicativa, observar o que pode ser dito naquele momento, observar o que o estilo verbal demanda, bem como o que deve ser a construção composicional. Corrobora, desse modo, Bakhtin (2000), em face de sua argumentação de que, para existir a interação, é preciso haver o domínio, ao mesmo tempo, das formas da língua como meio de discurso que se materializa nos gêneros discursivos.

E essa organização que acaba se formando nas atividades das pessoas colabora para que a interação na sociedade flua melhor. A esse respeito diz Bakhtin (2000, p. 302): "Se não existissem os gêneros do discurso e se não os dominássemos, se tivéssemos de criálos pela primeira vez no processo da fala, a comunicação verbal seria quase impossível".

Dentre os vários gêneros, o autor diz haver os primários e os secundários. Os primários concernem a um gênero que se materializa nas interações mais simples do cotidiano, não exigindo uma elaboração mais acurada da linguagem. Já os secundários são aqueles que exigem do sujeito uma organização de sua participação, sempre com um cuidado necessário na formalização da sua enunciação, pois é um gênero mais complexo. Nesse caso, é na modalidade escrita que ele é mais recorrente (BAKHTIN, 2000).

A esse respeito anuncia Bakhtin (2000, p. 281-282): “A distinção entre gêneros primários e gêneros secundários tem grande importância teórica, sendo esta a razão pela qual a natureza do enunciado deve ser elucidada e definida por uma análise de ambos os gêneros". Para o autor, "a inter-relação entre os gêneros primários e secundários de um lado, o processo histórico de formação dos gêneros secundários do outro, [eis] o que esclarece a natureza do enunciado" (BAKHTIN, 2000, p. 282).

Além disso, em virtude das várias esferas das atividades humanas, gêneros vão envelhecendo, outros vão sendo ressignificados e até criados. É uma dinâmica que acompanha o dinamismo que é a vida. Enfim, é por meio dos gêneros que as pessoas organizam suas experiências, atribuindo-lhes sentidos (BAKHTIN, 2000).

E insiste o autor que não se deve desconsiderar "a natureza do enunciado" e as especificidades de gênero que identificam as variedades do discurso que ocorrem em qualquer área do estudo linguístico. Caso isso aconteça, induz "ao formalismo e à abstração, desvirtua a historicidade do estudo, enfraquece o vínculo existente entre a língua e a vida" (BAKHTIN, 2000, p. 282), o que, vale dizer, ocorre muitas vezes em uma sala de aula.

Portanto, o que constitui um gênero é a sua relação com uma situação social de interação e não suas propriedades formais. Ademais, os gêneros inserem-se numa ordem enunciativa; ou seja, cada esfera da comunicação proporciona "tipos relativamente estáveis de enunciados".

Bakhtin (2000, p. 308) explica o que é o enunciado:

O enunciado é um elo na cadeia da comunicação verbal. Representa a instância ativa do locutor numa ou noutra esfera do objeto do sentido. Por isso, o enunciado se caracteriza, acima de tudo, pelo conteúdo preciso do objeto do sentido. A escolha dos recursos linguísticos e do gênero do discurso é determinado principalmente pelos problemas de execução que o objeto do sentido implica para o locutor (o autor). É a fase inicial do enunciado, a qual lhe determina as particularidades de estilo e composição. 
Nesse sentido, há de se considerar o que já foi apontado anteriormente, ou seja, que o conteúdo temático, o estilo e a construção composicional, de acordo com Bakhtin (2000, p. 279), "fundem-se, indissoluvelmente, no todo do enunciado, e todos eles são marcados pela especificidade de uma esfera de comunicação". Resultam, portanto, da intersecção das seguintes dimensões: a) o conteúdo temático - o que é possível dizer naquela situação, ou seja, trata-se dos conteúdos que se tornam comunicáveis por meio daquele gênero; b) o estilo verbal: o estilo de determinado gênero em uma dada esfera da atividade e da comunicação humana; c) a construção composicional: modo como as esferas sociais formam os enunciados (BAKHTIN, 2000).

Daí a importância de se trabalhar gêneros que circulam tanto na esfera acadêmica como na profissional, preparando o ser humano para os diversos contextos em que determinados gêneros são solicitados. E se são tipos relativamente estáveis de enunciados, podem orientar procedimentos e possibilitar que, por meio deles, sejam pensadas oficinas de linguagem - como no caso do gênero memorial descritivo que aqui é tratado -, de modo que o estudante possa se apropriar desse modelo de enunciado. E como se constitui o gênero memorial?

Rego (2014, p. 791) responde dizendo que "o memorial se constitui, antes de mais nada, num instrumento de avaliação de competência e mérito de um percurso acadêmicoprofissional, a ser examinado por uma comissão julgadora". Argumenta que "não se trata de um gênero simples" e que "o memorial estabelece entre o autor e o leitor uma série de mediações e filtros singulares" (REGO, 2014, p. 791). Portanto, é um gênero secundário, conforme preconiza Bakhtin (2000).

Nessa perspectiva, o gênero memorial descritivo é um gênero que já foi conformado tanto acadêmica como profissionalmente e sobre ele é possível debruçar-se, observando os três elementos antes mencionados: conteúdo temático, estilo e construção composicional.

\section{CONSTRUINDO A PROPOSTA}

A escritura do memorial descritivo aqui apresentado, pela sua especificidade de encaminhamentos, configurou-se como pesquisa-ação (THIOLLENT, 1988).

Ao descrever o que é uma pesquisa-ação, Thiollent (1988, p. 75) refere que se trata do momento, no âmbito educacional, em que "os pesquisadores em educação estariam em condição de produzir informações e conhecimentos de uso mais efetivo, inclusive ao nível pedagógico". E esse tipo de pesquisa aponta para a elaboração de um planejamento que, ao ser executado, possibilita atingir determinados "efeitos, conceber objetos, organizações, práticas educacionais e suportes materiais com características e critérios aceitos pelos grupos interessados" (THIOLLENT, 1988, p. 75). Por certo, ao término das estratégias pedagógicas estabelecidas, tem-se uma proposta didática que pode ser utilizada em situações de ensino com contextos similares.

Como o memorial descritivo é utilizado tanto na esfera acadêmica como em espaços relacionados a algumas profissões, sendo comumente solicitado como prerrequisito para o ingresso na esfera do mundo do trabalho, compreende-se que esse gênero deve ser tomado como prática de ensino-aprendizagem em todos os níveis e em todas as modalidades da educação profissional. 
No caso do curso em Bacharelado em Secretariado Executivo, aqui em tela, optouse pela criação de oportunidades para que os alunos pudessem vivenciar situações de uso real da língua, concretizada por meio do gênero memorial descritivo. A intenção foi levar a refletir em que contextos esse gênero é requisitado.

\subsection{PRIMEIRA ETAPA}

A primeira decisão estava tomada: cada estudante deveria produzir o seu próprio memorial, o que demandou tratar das seguintes questões: como fazer para que eles produzissem? Diante da resistência/receio na produção de textos mais longos, e até mesmo das dificuldades na escrita de parte dos/as estudantes, como fazer para, inicialmente, provocar certo "desbloqueio" para a escrita? Para tanto, propôs-se uma atividade na qual pudessem ativar o conhecimento prévio sobre memórias.

Moreira (2011, p. 26), ao tratar sobre essas memórias, reporta-se a Ausubel (2003) e ao conceito deste de subsunçores: "estrutura prévia cognitiva (i.e., os conhecimentos prévios e sua organização hierárquica) e que seria o principal fator [...]" a afetar "a aprendizagem e a retenção de novos conhecimentos". Trata-se de "proposições, modelos mentais, construtos pessoais, concepções, ideias, invariantes operatórios, representações sociais e, é claro, conceitos já existentes na estrutura cognitiva de quem aprende" (MOREIRA, 2011, p. 28).

Ainda, de acordo com Moreira (2011, p. 26), esse conhecimento precedente é de extrema importância, pois a organização deste é que possibilita que o novo ganhe significados, se integre e se diferencie em relação ao que já existe, tornando-se mais "estável, mais diferenciado, mais rico, mais capaz de ancorar novos conhecimentos".

Para acionar esses conhecimentos prévios, propôs-se que os estudantes sentassem em um círculo e foi-lhes solicitado falar sobre sua educação básica, destacando o que tinha sido bom, mas também aquilo que os tinha marcado de forma negativa.

Uma das perguntas feitas era relativa à língua portuguesa, na perspectiva de apontar como os estudantes viam essa disciplina, que memórias tinham do ensino dela. Muitos disseram que português tinha sido difícil, pois havia muitas regras, precisavam decorar e conjugar verbos, mostrando, em muitas situações, que ao ensino da língua materna subjazia a língua como sistema, uma abstração, e não o processo de interação.

Fundamental nesse ponto é uma reflexão sobre o que é importante no trabalho por meio dos gêneros. Nesse sentido, as contribuições de Bakhtin (2000) são válidas, dada a compreensão de que o ensino precisa estar vinculado às ações cotidianas do ser humano, para que tenha sentido para os estudantes, o que exige mudança de atitude do professor em sua forma de debruçar-se sobre a língua. Para ele, é imperativo abarcar o aprofundamento das modalidades dos gêneros, uma vez que representam a língua em uso, uma língua viva:

\footnotetext{
A língua materna - a composição de seu léxico e sua estrutura gramatical -, não a aprendemos nos dicionários e nas gramáticas, nós a adquirimos mediante enunciados concretos que ouvimos e reproduzimos durante a comunicação verbal viva que se efetua com os indivíduos que nos rodeiam (BAKHTIN, 2000, p. 301).
} 
Houve a necessidade, portanto, da criação de momentos em que percebesse a língua não somente como estrutura, mas como algo que faz parte do cotidiano e tem suas formas de dizer.

Aos poucos, os estudantes foram acionando suas memórias. Foi um momento muito descontraído, com histórias engraçadas; outras nem tanto. O primeiro obstáculo, ao que tudo indicava, tinha sido vencido, pois as recordações foram acionadas e os participantes do diálogo refletiram sobre como elas implicaram a construção da individualidade de cada um e as escolhas futuras que teriam pela frente. Até esse momento não se falou no gênero memorial descritivo.

Passada essa estação, foi solicitado o registro dessa etapa de suas vidas mediante um texto com relatos sobre sua vida estudantil na educação básica (incluindo o que se lembravam, o que consideraram importante, do que não gostaram, se havia uma disciplina preferida, como era sua escola na época, o que do aprendido teria influenciado a sua vida). Ao final, deveriam dizer por que escolheram o curso superior Bacharelado Secretariado Executivo. Enfim, deveriam abordar as lembranças que ficaram registradas em sua memória.

Grande parte dos textos produzidos ia além de duas páginas. ${ }^{4}$ Mais que a aprendizagem na escola, muitos trouxeram experiências de vida e memórias carregadas de vivências familiares, as dificuldades que os pais enfrentaram, a dureza da vida, as distâncias que alguns tiveram de percorrer para poder estudar, a falta de material para ir à escola, a rigidez e agressividade de alguns dos pais. Enfim, relatos que mexeram com eles e com quem os leu. Uma das alunas mencionou que chorou quando estava escrevendo. Outra referiu que não queria escrever porque determinadas lembranças doíam muito.

Parte do que foi registrado naquela primeira escritura pode ser observado nos excertos seguintes:

Minha mãe veio da roça [...] não tinha mais que o ensino fundamental completo. Trabalhou desde muito nova como babá, doméstica em várias casas, e em uma lavanderia [...]. (M.1 ${ }^{5}$ ).

Fomos os primeiros da família a obter graduação. (M. 2).

Minha criação sempre foi voltada para ser "certinha". (M. 7).

Meu pai era pedreiro, pegava o serviço e colocava pessoas para trabalhar com ele, era um homem trabalhado. (M. 11).

Sou filha de uma mulher muito guerreira [...]. (M. 12).

[...] sou filha de pais que só cursaram até a $6^{\circ}$ série do ensino fundamental, eram lavradores e moravam no sítio. (M. 15).

\footnotetext{
${ }^{4}$ Dois textos continham mais de cinco páginas.

${ }^{5}$ Os memoriais são representados por M.1 (Memorial 1), M.2 (Memorial 2) e assim sucessivamente.
} 
Esses apontamentos levam a Morin (2014, p. 37), que assim diz: "Conhecer o humano não é separá-lo do Universo, mas situá-lo nele. [...] todo conhecimento, para ser pertinente, deve contextualizar seu objeto. 'Quem somos nós?' é inseparável de 'Onde estamos, de onde viemos, para onde vamos?"'. E isso se tentou fazer, ao acionar as memórias que constituíram esses estudantes. Afinal, os seres humanos são as vozes dos que os antecederam (BAKHTIN, 2009).

Se, no início, a intenção era fazer com que os estudantes escrevessem sobre como havia sido a educação básica, ao término do texto deveriam apontar como ocorreu a decisão pelo bacharelado em secretariado.

Observa-se que a escolha do curso superior se deu de vários modos. Alguns não tiveram outra opção. Outros desejavam o curso desde o ensino médio. E ainda alguns optaram por ele porque poderia ajudá-los a passar em concurso público. Vejam-se alguns trechos:

Meu intuito ao voltar a estudar era para passar em concurso, pela procura de novos desafios [...]. (M.2).

Desde criança, eu me imaginava trabalhando em um escritório [...]. (M.4).

[...] a escolha que fiz foi e é a mais apropriada para atingir os meus objetivos de ser um servidor público [...]. (M.7).

Embora o mercado de trabalho na cidade não reconhecesse a competência desse profissional, eu optei por essa graduação. (M.8).

A escolha do curso está associada a minha experiência profissional e estudantil. Deste o período do ensino básico me interessei pelas organizações de eventos e liderança de turma [...]. (M.10).

[...] em 2012 fui selecionada para trabalhar como assessora executiva em uma empresa de comunicação da capital, o que me motivou a buscar o curso de secretariado executivo. (M.13).

Uma primeira constatação: mediante uma provocação, a escritura do texto sai! Portanto, era preciso animá-los para a escritura do memorial descritivo, fazendo o recorte na aprendizagem durante o ensino superior e, caso já trabalhassem, em sua atuação como profissional, ou seja, focar no conteúdo temático.

Nesse sentido, entendemos com Morin (2014, p. 24) que: "Todo conhecimento constitui, ao mesmo tempo, uma tradução e uma reconstrução, a partir de sinais, signos, símbolos, sob a forma de representações, ideias, teorias, discursos.” Afinal, conhecer e trabalhar com o gênero memorial descritivo ativaria as estruturas cognitivas já estabelecidas (MOREIRA, 2011) e, ao mesmo tempo, outras seriam acionadas, provocadas.

E essas estruturas já conhecidas e as novas a serem construídas conduzem a Vygotsky (1998 apud REGO, 2000), que indica a existência de dois níveis de desenvolvimento humano: aquele em que as conquistas já estão efetivadas - o conhecido (registrado como o conceito de subsunçor de Ausubel); e o nível de desenvolvimento potencial, relativo às conquistas que podem ser construídas obtidas com o auxílio de outra pessoa; ou seja, passíveis de transformar o desenvolvimento proximal em desenvolvimento real. 
O papel principal do docente é mediar a aprendizagem. Para tanto, precisa estabelecer ações capazes de fazer o estudante sair da sua zona real (sua estrutura estabelecida), passar pelo desenvolvimento potencial e, então, chegar novamente a uma etapa real de conhecimento.

\subsection{SEGUNDA ETAPA}

Com o primeiro texto produzido, era a hora dialogar e apresentar o gênero memorial descritivo como instrumento de ação social.

Nesse momento, foram analisados alguns memoriais de formação em que os estudantes deveriam, seguindo um roteiro, ${ }^{6}$ identificar o plano geral do memorial, observando as características dele. Deveriam observar o discurso predominante, suas marcas linguísticas de pessoa e de espaço, tipos de frases e o tempo verbal predominante. Além disso, observar os mecanismos enunciativos e verificar se havia marcas de subjetividade no memorial e a respectiva ocorrência ou não de modalizadores. Também deveria ser considerada a polifonia, verificando-se como o autor do memorial se reportava ao discurso alheio.

Ainda precisariam notar o funcionamento do texto, seus conectores, observar qual o tipo predominante de organização (narrativa, descritiva, dialógica, argumentativa...), analisando qual a função dessa organização em relação ao gênero memorial; assim como os mecanismos de textualização: que tempo verbal predomina e quais os mecanismos de conexão mais recorrentes, o registro formal ou informal, as escolhas lexicais.

$\mathrm{O}$ resultado dessa análise foi amplamente discutido. Tratou-se de um momento bastante produtivo, pois permitiu que os estudantes se aproximassem desse gênero. Foi possível ampliar os conhecimentos acerca do que contempla o memorial, de como ele deveria ser organizado, do que poderia ser dito, das formas verbais mais recorrentes, do envolvimento subjetivo do autor, além de outros aspectos.

Após essa parada, foram estabelecidas, coletivamente, sugestões sobre os elementos que deveriam ser contemplados, no que diz respeito ao que Bakhtin (2000) aponta como o conteúdo temático, o estilo e a construção composicional.

\footnotetext{
Os enunciados refletem as condições específicas e as finalidades de cada referido campo não só por seu conteúdo (temático) e pelo estilo da linguagem, ou seja, pela seleção dos recursos lexicais, fraseológicos e gramaticais da língua, mas, acima de tudo, por sua construção composicional. (BAKHTIN, 2000, p. 279).
}

Marcuschi (2008) aponta que o memorial descritivo está inserido no domínio discursivo instrucional (científico, acadêmico e educacional) e se apresenta na modalidade escrita da língua. Para o autor, o domínio discursivo é "uma esfera da vida social ou institucional na qual se dão práticas que organizam formas de comunicação e

\footnotetext{
${ }^{6}$ Roteiro apresentado no item: “Uma proposta metodológica possível”, deste texto.
} 
respectivas estratégias de compreensão" (MARCUSCH, 2008, p. 194). Além disso, argumenta que esses domínios "operam como enquadres globais de superordenação comunicativa, subordinando práticas sociodiscursivas orais e escritas que resultam nos gêneros" (MARCUSCH, 2008, p. 194).

Vieira (2017, p. 292) explana que os "memoriais são escritos na primeira pessoa do singular, da mesma forma que as cartas, as confissões, os diários e as memórias. Esse gênero de escrita de si expõe as razões do sujeito na sua parcialidade e subjetividade".

Por sua vez, Severino (2000, p.176) assinala o que compõe a estrutura do memorial:

\begin{abstract}
Enquanto texto narrativo e interpretativo recomenda-se que o Memorial inclua em sua estrutura redacional subdivisões com tópicos/títulos que destaquem os momentos mais significativos. No mínimo, aqueles mais gerais, como os momentos de formação, da atuação profissional, da produção científica etc. Melhor ficaria, no entanto, se esta divisão já traduzisse uma significação temática que realçasse a especificidade daquele momento.
\end{abstract}

Sendo assim, a decisão dos estudantes foi focar nos conteúdos aprendidos durante os semestres, evidenciando, caso fosse de seu interesse, a área na qual estavam fazendo o projeto de estágio (TCC), o que colaboraria para a fundamentação do trabalho de conclusão do curso que estava em construção. Além disso, deveriam registrar as participações e organização de eventos.

Ao mesmo tempo, foram decididas três datas para a entrega do memorial para correção da docente e solicitação dos ajustes necessários. Entre uma data e outra propôsse um intervalo de vinte dias, para que, após a leitura da docente, houvesse tempo para o aprimoramento do memorial. Também foi decidido que o texto seria formatado de acordo com as normas da ABNT.

\title{
3.3 TERCEIRA ETAPA: DEVOLUTIVA DAPRIMEIRA PRODUÇÃO - MOMENTO DE SE AFASTAR DAS SUBJETIVIDADES
}

Como a primeira proposta objetivava falar sobre a experiência com a educação básica e apareceram muitas reflexões relacionadas à vida familiar, com raras exceções, a primeira versão do memorial chegou, ainda, recheada das dificuldades pelas quais os estudantes passavam no curso de secretariado, na vida familiar e profissional. Mas era a hora de trazer as reflexões teóricas do curso, estabelecendo relações com sua prática.

Para aperfeiçoar o texto e deixá-lo com uma escrita mais próxima do desejado, com ampliação do registro das memórias relacionadas com a formação, foram lançadas algumas perguntas para levar os estudantes a refletir, especialmente, sobre seu curso superior, sua aprendizagem e em que isso implicaria ou implicava em sua vida profissional. As perguntas principais tiveram três enfoques: a. O profissional: Qual o papel, na sociedade, que o acadêmico exerce a partir da sua formação? Qual a relevância da profissão no mercado de trabalho? Quais suas principais atribuições? Quem é o profissional secretário executivo? Qual o papel do(a) secretário(a) executivo(a) numa empresa? Que relação você estabelece com o que já aprendeu na academia e a sua profissão? b. As aprendizagens: $\mathrm{O}$ que foi aprendido com mais profundidade durante o 
curso? O que aprenderam que consideram importante para sua atuação profissional? Quais foram os fatos particulares, ocorridos em cada uma dessas etapas, que mais marcaram esse processo? Quais as maiores dificuldades durante o curso? Quais as maiores afinidades? c. Perspectivas para o futuro: Em que área(s) do curso gostaria de se especializar? Por quê? Pretende atuar como secretário(a)? Por quê?

\subsection{TERCEIRA ETAPA: SEGUNDA VERSÃO DO MEMORIAL}

A segunda versão teve como objetivo principal orientar os estudantes para refletir sobre a prática da escrita e da reescrita textual, a fim de adequar o seu texto à situação de comunicação estabelecida. Então, além de observar o que deveria ter sido exposto sobre o conteúdo temático, teve como foco avaliar se a escrita estava adequada ao contexto, ao destinatário, se o memorial refletiu criticamente sobre os fatos narrados; se considerou os aspectos essenciais da construção composicional que implica o gênero da ordem do relatar e descrever (DOLZ, NOVERRAZ e SCHNEUWLY, 2004) ${ }^{7}$; se fez uso adequado de organizadores textuais, dando progressão ao texto, enfim, aquilo que diz respeito à estruturação geral interna do enunciado.

Por isso, foi o momento de se observar e reconhecer o conteúdo temático (memórias pessoais, acadêmicas e profissionais), verificar se o memorial refletiu criticamente sobre os fatos narrados, seu estilo ou organização textual (uso dos indicadores de relato, verbo no pretérito, relatores temporais, se fez uso adequado de organizadores textuais, dando progressão ao seu texto) e estilo, isto é, os recursos lexicais e fraseológicos utilizados (nesse caso o registro formal escrito e em primeira pessoa). Foi o momento de se observar o uso adequado da norma culta da língua, com aspectos relacionados ao discurso polifônico: citação direta, indireta (paráfrase).

Nessa etapa, juntos, professor e aluno olharam o memorial produzido para ver o que deveria ser modificado, acrescentado, corrigido. Fez-se, então, um roteiro no qual o aluno deveria se pautar para analisar o seu memorial, a saber: foram acionadas sequências narrativas e descritivas na construção do texto? A escolha de recursos lexicais e semânticos está de acordo com a situação de produção do discurso? Foram utilizados elementos linguísticos responsáveis pela organização do espaço-tempo - na sequência do narrar? Os mecanismos coesivos estão empregados de modo a assegurar a textualidade? Como se organiza a presença de vozes sociais no texto? Há marcas de subjetividade no texto? Cite-as se houver. O enunciador conseguiu refletir sobre a construção de sua identidade como sujeito social e histórico, permeado pelas vivências familiar, pessoal, acadêmica e profissional? Como o enunciador revela a sua autoria no texto?

Ao término dessa análise, foi produzida a reescrita levando em conta aquilo que ainda era necessário ajustar. E assim chegou-se à última estação: o memorial pronto - a terceira versão do memorial acadêmico descritivo. Parte dessa produção é compartilhada em anexo.

\footnotetext{
${ }^{7}$ Dolz, Noverraz e Schneuwly (2004), levando em consideração as capacidades de linguagem dominantes dos sujeitos, agrupam os gêneros textuais em cinco ordens: narrar, relatar, argumentar, expor, instruir ou prescrever.
} 
Diante do trabalho realizado, consoante os resultados obtidos, uma proposta didática pôde ser estabelecida, como segue.

\section{UMA PROPOSTA METODOLÓGICA POSSÍVEL}

O gênero memorial descritivo tem como foco principal a esfera acadêmica e, em escala menor, espaços relacionados a algumas profissões que exigem, muitas vezes, a apresentação de um memorial como prerrequisito para o ingresso no trabalho.

Por isso, uma das características que a produção desse gênero exige é o diálogo com a vida pessoal, a história acadêmico-formativa e a relação estabelecida, na grande maioria das vezes, com sua atuação profissional.

Estabelecidos esses parâmetros sobre o gênero, uma proposta de trabalho pode comportar os seguintes passos:

1) Ativação do conhecimento prévio sobre o gênero e o tema a serem abordados mediante diálogo e posterior escritura das memórias sobre a vivência na educação básica;

2) Apresentação do gênero por meio da leitura e análise de memorial descritivo, seguindo um roteiro, observando aspectos relacionados ao conteúdo temático, estilo e construção composicional (o roteiro deve conter questões que levem o estudante a refletir sobre o que constitui o gênero);

Possível roteiro ${ }^{8}$ no reconhecimento dos elementos principais de um memorial descritivo, a saber: conteúdo temático, plano composicional e estilo.

Em que momentos o memorial descritivo é solicitado? Por quê? O que vocês sabem sobre memorial descritivo? Enfim, buscar saber o porquê dessa atividade de comunicação científica na vida social.

Construção composicional: Condições de produção: autor do memorial analisado e a sua função social (Quem é ele? Que papel social desempenha?) finalidade?

Quando o memorial foi escrito? Para quem ou para qual instituição foi destinado? Qual a sua

- Estrutura: quantas páginas o texto possui? Como está dividido o conteúdo?

- Aspectos linguísticos: O texto está escrito em que pessoa? Qual o tipo verbal predominante?

Conteúdo temático: Qual o tema principal tratado pelo autor? Descreva-o(s). O autor apresenta sua identidade apontando os aspectos acadêmico, profissional, subjetivo-pessoal? Reflete sobre eles? Reflete sobre sua prática? Faz prospecções para sua vida profissional, acadêmica ou pessoal?

Estilo: Que sequências discursivas/textuais predominam no memorial em análise? Como se organiza a presença de vozes sociais no texto? Que tipo de discurso utilizado é mais recorrente? Por que você acredita que ele usou mais este tipo de discurso? A escrita é mais objetiva ou mais subjetiva? Destaque partes dessa escrita, comprovando os traços subjetivos e objetivos. Quais as características enunciativas do autor? Há modalizadores presentes? Você percebe a autoria no texto? Como ela se mostra?

\footnotetext{
${ }^{8}$ Este roteiro levou em consideração as leituras de Bakhtin (2000, 2009), Brandão (2002) e de outras obras que tratavam sobre gênero e ensino como em Rojo (2000), Koch (2002), Voese (2004), Marcuschi (2008), entre outros. Neste momento, para este trabalho, ainda não havia familiaridade com a discussão sobre sequência didática, como apresentado por Dolz, Noverraz e Schneuwly (2004). Posteriormente a essa atividade com os memoriais, começou-se estudo dessa temática.
} 
3) Sistematização das observações pontuadas pelos estudantes acerca do conteúdo temático, estilo e construção composicional (após a discussão e análise das respostas, delinear o que é recorrente no gênero - o que é mais ou menos estável -, descrevendo os principais interlocutores do memorial e estabelecendo as esferas em que o gênero é requerido e o seu modo de organização.

4) Produção inicial do gênero mediante um roteiro preestabelecido coletivamente, com posterior atividade de refazimento, observando elementos próprios da composição do gênero: conteúdo temático, estilo e construção composicional - seguir o roteiro de questões elencadas pelo docente (descritas nas estações 2 e 3 ).

5) Transformação do memorial em objeto de estudo, seguindo análise de um roteiro em que se preconizam os aspectos desse gênero.

\begin{tabular}{|l} 
Possível roteiro para a análise dos memoriais produzidos em sala: \\
O posicionamento enunciativo está coerente com a ação de linguagem materializada na produção \\
do gênero memorial? \\
Foram acionadas sequências narrativas e descritivas na construção do texto? \\
A escolha de recursos lexicais e semânticos está de acordo com a situação de produção do \\
discurso? \\
Foram utilizados elementos linguísticos responsáveis pela organização do espaço-tempo - na \\
sequência do narrar? \\
Os mecanismos coesivos estão empregados de modo a assegurar a textualidade? \\
Como se organiza a presença de vozes sociais no texto? \\
Há marcas de subjetividade no texto? \\
O enunciador conseguiu refletir sobre a construção de sua identidade como sujeito social e \\
histórico, permeado pelas vivências familiar, pessoal, acadêmica e profissional? \\
Oomo o enunciador revela a sua autoria no texto? \\
pessoal? faz projeções para seu futuro? Apresenta seus objetivos acadêmico, profissional ou \\
O texto segue as normas da ABNT?
\end{tabular}

6) Versão final: o memorial volta a ser visto na totalidade, a fim de ser verificado se os estudantes demonstraram ter compreendido esse gênero.

\section{CONSIDERAÇÕES FINAIS}

Bakhtin (2000) afirma que os gêneros são apropriados pelas pessoas durante a trajetória de sua vida e refletem a sua participação em determinada comunidade e em situações específicas de interação. Em cada uma dessas situações, que ele chama de esferas comunicativas, o ser humano vai conformando gêneros que acabam se tornando modelos para determinados contextos. Um desses modelos estabelecidos é o memorial descritivo, que faz parte tanto do mundo do trabalho como do acadêmico. É um gênero secundário que, pela sua especificidade e uso em determinadas esferas, deveria ser ensinado nos cursos de graduação. E foi o que se propôs a fazer. 
O resultado do trabalho possibilitou que os alunos refletissem sobre sua trajetória, destacando os principais aspectos do que os constituiu subjetivamente, bem como o que se refere à formação acadêmico-profissional, apontando o que foi mais importante.

Quando se fala em ensinar tal gênero para tal contexto, é importante refletir sobre a importância que tem a educação no cotidiano das pessoas e o que ela deve provocar em suas vidas. Morin $(2014$, p. 22) assim assinala: "A educação deve favorecer a aptidão natural da mente para colocar e resolver os problemas e, correlativamente, estimular o pleno emprego da inteligência geral". E diz que, quando se fala em meios que "permitem assegurar a formação e desenvolvimento de um ser humano", dever-se-ia se saber que "a missão do didatismo é encorajar o autodidatismo, despertando, provocando, favorecendo a autonomia do espírito" (MORIN, 2014, p. 10-11).

Os memoriais escritos pelos estudantes apresentam uma reflexão sobre sua vida pessoal, acadêmica e profissional e apontam uma autonomia do espírito no que diz respeito às marcas que cada etapa de sua vida deixou.

E o reflexo dessa atividade de escritura foi percebido em vários momentos em sala. $\mathrm{Na}$ aula da saudade, uma estudante pontuou que, ao produzir o memorial descritivo, lembranças importantes foram acionadas, momentos admiráveis foram lembrados e registrados. Outra aluna assinalou em seu memorial: Que felicidade ter chegado até aqui. Ter escrito esse memorial me fez lembrar todos os obstáculos superados" (M. 12). Em outro momento, no qual se trabalhou o gênero carta de intenção, os alunos buscaram em seus memoriais os registros para fundamentar sua escritura. Demonstraram entender que os gêneros, de alguma maneira, se tocavam - o que poderia ser reportado ao que Marcuschi (2008, p. 163-170) designa de intergenericidade e intertextualidade.

Trabalhar com gêneros que circulam socialmente, tomando a língua materializada nos diversos contextos de interação, possibilita um trabalho bem produtivo, pois se trata de atividade que possui sentido para os estudantes.

Em anexo, apresenta-se uma pequena parte $^{9}$ do que foi produzido pelos estudantes, acrescido de algumas das reflexões sobre sua vida pessoal, acadêmica e profissional.

\section{REFERÊNCIAS}

BAKHTIN, M. Estética da criação verbal. Tradução: Maria Ermantina Galvão G. Pereira. 3. ed. São Paulo: Martins Fontes, 2000.

BAKHTIN, M. (V. N. Volóchinov). Marxismo e filosofia da linguagem: problemas fundamentais do método sociológico na ciência da linguagem. Tradução: Michel Lahud e Yara Frateschi Vieira. 13. ed. São Paulo: Hucitec, 2009.

BRANDÃO, H. N. Introdução à análise do discurso. 8. ed. Campinas, SP: Unicamp, 2002. COSTA, S. R. Dicionário de gêneros textuais. 3. ed. Belo Horizonte: Autêntica, 2014.

DIONÍSIO, Â. P.; MACHADO, A. R.; BEZERRA, M. A. (Org.). Gêneros textuais e ensino. 2. ed. Rio de Janeiro: Lucerna, 2003.

DOLZ, J.; NOVERRAZ, M.; SCHNEUWLY, B. Sequências didáticas para o oral e escrita: apresentação de um procedimento. In: ROJO, R.; CORDEIRO, G. S. (Org.). Gêneros orais e escritos na escola. Campinas, SP: Mercado de Letras, 2004. p. 95-128.

\footnotetext{
${ }^{9}$ Os memoriais transitaram entre seis e onze páginas.
} 
HANKS, W. F. Língua como prática social: das relações entre língua, cultura e sociedade a partir de Bourdieu e Bakhtin. Organização e apresentação: Anna Cristina Bentes; Renato C. Rezende; Marco Antônio Rosa Machado. Tradução: Anna Cristina Bentes et al. São Paulo: Cortez, 2008.

KOCH, I. G. V. Desvendando os segredos do texto. 2. ed. São Paulo: Cortez, 2002.

MARCUSCHI, L. A. Produção textual: análise de gêneros e compreensão. São Paulo: Parábola, 2008.

MARTINS, J. A pesquisa qualitativa. In: FAZENDA, I. (Org.). Metodologia da pesquisa educacional. 9. ed. São Paulo: Cortez, 2004. p. 47-58. (Biblioteca da Educação, Série I, Escola; v.11).

MOREIRA, M. A. Aprendizagem significativa: a teoria e textos complementares. São Paulo: Editora Livraria Física, 2011.

MORIN, E. [1921]. A cabeça bem-feita: repensar a reforma, reformar o pensamento. Tradução: Eloá Jacobina. 21. ed. Rio de Janeiro: Bertrand Brasil, 2014.

OLIVEIRA, J. L. de. Texto acadêmico: técnicas de redação e de pesquisa científica. 8. ed. Petrópolis: Vozes, 2012.

REGO, T. C. Vygotsky: uma perspectiva histórico-cultural da educação. 10. ed. Petrópolis, RJ: Vozes, 2000.

REGO, T. C. Trajetória intelectual de pesquisadores da educação: a fecundidade do estudo dos memoriais acadêmicos. Revista Brasileira de Educação, v. 19, n. 58, jul.-set. 2014.

ROJO, R. (Org.). A prática de linguagem em sala de aula: praticando os PCNs. São Paulo: EDUC; Campinas: Mercado de Letras, 2000.

SEVERINO, Antonio Joaquim. Metodologia do trabalho científico. 24. ed. rev. e atual. São Paulo: Cortez, 2016.

THIOLLENT, M. Metodologia da pesquisa-ação. 4. ed. São Paulo: Cortez, 1988.

VIEIRA, C. E. Exercício de escrita de si: uma trajetória intelectual no âmbito do ensino e da pesquisa em história da educação. Educar em Revista, Curitiba, n. 63, p. 291-312, jan.-mar. 2017.

VOESE, I. Análise do discurso e o ensino da língua portuguesa. São Paulo: Cortez, 2004.

\section{ANEXO - REGISTROS E REFLEXÕES}

\section{A) REFLEXÕES SOBRE A VIDA PESSOAL E A FUTURA PROFISSÃO}

Alguns meses depois de estar estudando e trabalhando, percebi que estava com excesso de trabalho, minha função era atendimento ao cliente, porém exercia além do que "devia". É obvio que sou ciente de eficácia e eficiência, no entanto, já excedia o suficiente: atendimento ao cliente, operador de caixa, limpeza, produção de lanches, saladas de variados tipos, sucos, cafés quentes gelados etc. (M. 9)

A produção do memorial me fez refletir sobre minha vida acadêmica. Desde que iniciei o curso em 2013, só trabalhei e estudei, não fiz curso nenhum. Até mesmo um curso de inglês que sempre pensei e preciso fazer, não fiz. Eu tenho mania de deixar as coisas para depois e quando nos damos conta o tempo passou e não concluímos nada. (M. 16)

Diante de tudo, percebo abrindo a minha frente um leque de opções profissionais que eu posso considerar [...], sem deixar, à parte, o objetivo de passar em concursos, ou enredar-me na área de docência e, até mesmo, fundar uma empresa de assessoria executiva. Surge então um questionamento inquietante, de que não seria este um grande desafio para mim, como Secretária Executiva, ter uma visão empreendedora, e como estratégia focar nas mudanças mercadológicas que o exercício da profissão exige e me tornar competitiva para atender as necessidades pungentes? Preciso descobrir. (M. 2) 
E no final percebi que tudo que passei foi para me tornar uma profissional em secretariado com domínio de fala, e umas das principais armas da secretaria é ter uma boa oratória, saber persuadir, indagar, negar, sugerir e expor. (M. 1)

Senti imensa afinidade com as competências, habilidades e atitudes que o profissional de secretariado precisa ter, por serem características que eu já admirava em um ser humano de bem. Embora saiba que é um profissional que tem sua ética sob constante ataque, principalmente se for do sexo feminino, pois criaram um estereótipo negativo da mulher, como em submissão a todos os desejos de seu executivo, ainda que impróprios. (M. 5)

Conheci a profissão que já exercia na época, sem saber que existia código de ética, leis que regulamentam a profissão e todo potencial que um profissional da área de secretariado necessita desenvolver para desempenhar com eficácia suas funções e atuar em nível estratégico. (M. 12)

\section{B) REFLEXÕES SOBRE O CURSO}

Nesse período, aprendi, também, sobre o tema empreendedorismo. Descobri que empreender não é exatamente abrir uma empresa, mas sim descobrir uma oportunidade e transformá-la em algo lucrativo, não necessariamente monetário. Com o estudo desse tema, ficou claro que a arte de empreender não é algo exclusivamente inato, ou seja, um dom que poucas pessoas possuem, mas algo que qualquer pessoa pode desenvolver ao longo da vida, por meio do estudo ou por necessidade. Diante disso, é interessante que o secretário executivo desenvolva as características de um empreendedor, pois isso será um grande diferencial para a sua carreira, já que esse profissional terá capacidade para promover ações de melhorias para a empresa em que trabalha, visando ao crescimento dessa no mercado. (M.4)

Mas foi durante todo o curso de secretariado executivo que pude conhecer um pouco mais da sua história e suas funções. Aprendi que a minha profissão surgiu com os escribas e que sofreu uma evolução após a segunda guerra mundial. É que os homens que ocupava o cargo de Secretário morreram na batalha e daí abriu um espaço para as mulheres atuar como secretária. (M. 7)

Se tratando de conteúdo, o curso como um todo me fez perceber o quanto é importante ser polivalente, proativo, estar a par da economia nacional e mundial, saber outros idiomas, além disso, ampliou meu interesse pelo saber e me despertou para um novo alvo: a especialização, embora ainda indefinida. Afinal de contas a graduação não é o fim, mas sim o início de outra etapa, ainda mais precisa e minuciosa, a qual deverei escolher bem. (M. 8)

No curso, o que mais me identifiquei foi com a administração, gosto muito e trabalho na área. Também sou responsável por garantir a organização e a funcionalidade das rotinas das empresas e profissionais e liberais. $\mathrm{O}$ que eu aprendo no curso eu aplico na empresa que trabalho. Agreguei vários valores dentro da empresa, como trabalhar em equipe, se colocar no lugar do outro etc. (M. 11)

As experiências já vividas em minha profissão e os novos conhecimentos adquiridos através do curso de Bacharel em Secretariado Executivo Bilíngue trouxeramme a certeza de que a busca pelo constante aprimoramento profissional e o empenho na execução das atividades profissionais são os pilares para o sucesso do profissional de secretariado executivo. (M. 16) 


\section{C) REFLEXÕES SOBRE A PROFISSÃO/MUNDO DO TRABALHO}

Nessa nova função, eu consegui colocar em prática alguns conhecimentos obtidos no curso de secretariado executivo, pois o principal propósito do setor de controladoria é assessorar os diretores e gerentes nas tomadas de decisões, fornecendo dados e relatórios pelos quais consigam avaliar a viabilidade, lucros ou prejuízos antes da decisão. O perfil do curso de encaixou perfeitamente com o setor, pois assim como o profissional de secretariado, o controller deve ser ético, discreto, leal, proativo, dinâmico, possuir uma visão holística da empresa e postura formal. (M.3)

Desde então, venho exercendo atividades de assessoria executiva, estou cursando MBA em Assessoria Executiva, bem como o curso de Secretariado Executivo. Tudo vem acrescentando conhecimento e enriquecendo minha vida profissional. Atuo diretamente na área, apoiando gerentes e diretores em suas tomadas de decisões e o aprendizado durante o curso faz total diferença nessas tarefas diárias. A gestão estratégica é inteiramente ligada à função do secretário executivo, direciona efetivamente nos processos decisórios de uma empresa ou departamento. Outro aspecto importante que o curso tem feito a diferença é em relação às informações e processamentos de dados, esse conhecimento colaborou significativamente em minhas atividades de assessoria. (M. 13).

Experiência magna. ${ }^{10}$ As atividades desenvolvidas foram cem por cento relacionadas ao perfil do profissional de secretariado executivo: assessoria nas reuniões do Diretor, controle de agenda, aporte na organização de eventos oficiais... Resolução de conflitos. Oportunidade enriquecedora e, por meio desta, conheci um professor que fazia Doutorado no exterior e uma companheira de estágio indicou-me a ele para suporte na tabulação de dados que, para minha futura sorte, o tema era relacionado ao agronegócio. (M. 10).

O profissional de Secretariado Executivo deve estar preparado para atuar em diversas áreas. Mas um bom profissional não deve se acomodar apenas com um curso, tem que estar no processo de constante aprendizagem, e buscar fora o que acredita que pode ajudar a desenvolver suas competências e alavancar sua carreira. (M.6).

Um profissional de secretariado executivo pode se tornar um líder. O que é ser um líder? No meu ponto de vista, a liderança não é um cargo e, sim, vem do comportamento do ser humano para com os outros ao seu redor, é saber ter ética, respeitar a sociedade, as opiniões, saber ouvir e ao mesmo tempo dar um feedback construtivo. (M. 14).

Não basta saber usar as novas tecnologias, no sentido de operá-las para executar as atividades rotineiras da profissão. O profissional de secretariado precisa ter uma visão holística do mundo atual, saber lidar com os diferentes fatores que interferem no seu fazer diário e necessidades das diferentes instituições sociais, sejam elas públicas, privadas. (M. 15).

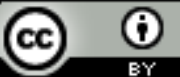

Este texto está licenciado com uma Licença Creative Commons Atribuição 4.0 Internacional.

\footnotetext{
${ }^{10}$ Referindo-se ao estágio durante o curso.
} 